\title{
When Fair Is Not Foul: Promoting Female Authorship in Gastroenterology Journals
}

\author{
Patrick A. Twohig ${ }^{1}$
}

Accepted: 20 April 2021 / Published online: 18 May 2021

(c) The Author(s), under exclusive licence to Springer Science+Business Media, LLC, part of Springer Nature 2021

Historically, gastroenterology (GI) has been underrepresented by women, with only $30 \%$ of trainees and $15 \%$ of practicing gastroenterologists being female [1-5]. Reasons for this gender gap have historically been attributed to factors such as time spent child rearing and the lack of role models, among others, all of which may contribute to decreased job satisfaction and reduced interest in pursuing GI as a career $[2,6]$.

Due to the low prevalence of females in GI, there has been a sparsity of female authors, speakers, panelists, and mentors for trainees. Although it may be concluded that there is a direct correlation between the overall low prevalence of females in GI and participation in scholarly activity, Bhatia et al. [7] describe in this issue of Digestive Diseases and Sciences that this alone does not explain the difference. One study showed that the proportion of female speakers at US and Canadian conferences increased from 24.6\% in 2007 to $34.1 \%$ in 2017 , although women are still underrepresented overall [8]. Improving female participation in conferences can be accomplished by promoting women to key organizational positions. One study found that including women in the membership of conference organizational committees increased female panelist involvement by up to $43 \%$ [9].

Bhatia et al. [7] provide the first study to assess gender disparities among authors of publications in three GI journals over a 20-year period-Gastroenterology, Gut, and the American Journal of Gastroenterology. Though other studies addressing this topic have been published in other specialties, this article focuses specifically on the field of gastroenterology. The authors found a significant increase in female first authors from $18.1 \%$ in 1997 to $42.7 \%$ in 2017 , and a significant, albeit smaller increase in last (senior)

Patrick A. Twohig

patwohig@gmail.com

1 Department of Gastroenterology and Hepatology, University of Nebraska Medical Center, 982000 Nebraska Medical Center, Omaha, NE 68198, USA authorship, 8.3\% in 1997 to $24.7 \%$ in 2017. As highlighted by the authors, primary and last authorship is a marker of academic opportunity and advancement, since being a first or senior author of a publication is an important component of career growth. Moreover, since women may have fewer opportunities to contribute to and influence their field, under-recognition of achievements and expertise along with decreased visibility in academic communities may result [10].

Bhatia et al. [7] highlight the gender disparity in editorial review boards, ranging from 12.5 to $15.6 \%$ in the three journals studied. Prior studies investigating trends in gender diversity among journal editorial boards and last authorship in GI journals have found a similar disparity [11-13]. Assessing the selection and promotion process for journal editorial board members and reviewers is essential for ensuring equal opportunity. The authors also discuss the influence that female last authorship can have on the probability of female first authorship. This finding has been shown in other medical fields, including surgery and radiology [14, 15]. This highlights the importance of mentorship in promoting involvement in scholarly activity and subsequent career development.

Multiple GI societies have created committees and interest groups that provide a platform for mentorship, networking, and career advancement. Encouraging women to get involved in professional communities can lead to subsequent professional growth and diversity. These advances have spawned a culture that promotes the identification of areas of interest and expanding mentorship to include individuals outside of one's home institution. A study assessing the results of the British Society of Gastroenterology's 'Supporting Women in Gastroenterology' initiative demonstrates the positive impact of a forum for mentorship and discussing personal challenges with others can have on female trainees in GI [16]. 


\section{The Future Is Now}

Creating a culture of inclusion and promotion within our institutions and organizations is essential to continue to attract the best and brightest to this immensely rewarding and evolving medical sub-specialty. Additional areas for consideration aimed at boosting continued progress of women in GI are outlined below:

\section{Academic Institutions}

Training aimed at raising awareness of unconscious biases significantly reduces gender disparities and promotes equal promotion and compensation practices, even with just a single 20-min session [17]. This may allow for greater equity in research funding and be a starting point for greater female representation in publications, as well as at academic conferences. GI departments should be evaluated regarding hiring and promotion practices in order to maintain equitable diversity, inclusion, and gender balance [18].

\section{Organizations}

Though the American College of Gastroenterology has seen an increase in women membership on committees from 19 to $26 \%$ from 2010 to 2016 [19], areas of leadership remain underrepresented with $24 \%$ of ACG committee chairs and $16 \%$ of board of trustees being women [19]. Continued growth, expansion, and promotion of special interest groups that provide a platform for networking, mentorship, and career advancement will be essential to increasing the percentage of leadership positions occupied by women in GI. The National Institute of Health provides grant funding for the advancement of women in biomedical careers. Similar methods can be employed by other organizations to promote scholarly activity and publication opportunities for women in GI [20].

\section{Future Directions}

Future studies could build from this article by assessing gender publication trends in other general GI journals of all impacts and also in subspecialty areas including advanced endoscopy, hepatology, colon cancer screening, and IBD, among others. Looking at the impact female mentors in scholarly activity outside of journal articles (e.g., abstracts, conference presentations, lectures) may also provide a different perspective on this issue. Assessing the percentage of first/last authorship by women in journals based on academic position may also add insight to improving areas of under-representation in the future.

\section{Conclusion}

Recognizing obstacles faced by women in GI, breaking them down and helping overcome them is the next step. Though encouraging leadership positions, journal authorship, and speaker invitations is merely scratching the surface, it is an auspicious start to a constantly evolving process. As institutions, journals, organizations, and other groups strive to grow and innovate while providing the best care and outcomes for their communities, successfully implementing systems aimed at reducing gender disparities and promoting inclusion across all levels of leadership is essential. Finally, implementation is only the first step, as monitoring the impact of changes that promote equity and adapting systems to continue inspiring future generations of gastroenterologists is key.

Funding No funding was used for this article.

\section{Declarations}

Conflict of interest PAT reports no conflict of interest.

\section{References}

1. Pallardy C. Male and female active physicians: 70 statistics by speciality. Becker's GI \& Endoscopy. February 13, 2015. http:// www.becker-sasc.com/gastroenterology-and-endoscopy/malefemale-active-physicians-70-statistics-by-specialty.html. Accessed March 25, 2021.

2. Shukla R. Current challenges facing women in gastroenterology: how do we move forward? ACG Case Rep J. 2016;3:144-145.

3. Kesavarapu K, Schwartz J, Ikonomi E, Ahmad A. What's holding women back? A review of gender inequality in gastroenterology in the USA. Lancet Gastroenterol Hepatol. 2019;4:898-900.

4. Woodward Z, Rodriguez Z, Jou JH et al. Gender disparities in gastroenterology fellowship director positions in the United States. Gastrointest Endosc 2017;86:595-599.

5. Diamond SJ, Thomas CR Jr, Desai S et al. Gender differences in publication productivity, academic rank, and career duration among U.S. academic gastroenterology faculty. Acad Med 2016;91:1158-1163.

6. Tomer G, Xanthakos S, Kim S et al. Perceptions of gender equality in work-life balance, salary, promotion, and harassment: results of the NASPGHAN task force survey. J Pediatr Gastroenterol Nutr 2015;60:481-485.

7. Bhatia S, Cotton CC, Kim E, et al. Gender and nationality trends in manuscripts published in prominent gastroenterology journals between 1997 and 2017. Dig Dis Sci. (Epub ahead of print). https://doi.org/10.1007/s10620-021-07021-2.

8. Ruzycki SM, Fletcher S, Earp M et al. Trends in the proportion of female speakers at medical conferences in the United States and Canada: 2007 to 2017. JAMA Netw Open. 2019;2:e192103. 
9. Casadevall A, Handelsman J. The presence of female conveners correlates with a higher proportion of female speakers at scientific symposia. MBio 2014;5:1-4.

10. Rabinowitz LG, Anandasabapathy S, Sethi A et al. Addressing gender in gastroenterology: opportunities for change. Gastrointest Endosc. 2019. https://doi.org/10.1016/j.gie.2019.08.039.

11. Jagsi R, Guancial EA, Worobey CC et al. The "gender gap" in authorship of academic medical literature-a 35-year perspective. N Engl J Med 2006;355:281-287.

12. Fox CW, Duffy MA, Fairborn DJ et al. Gender diversity of editorial boards and gender differences in the peer review process at six journals of ecology and evolution. Ecol Evol 2019;9:13636-13649.

13. Long MT, Leszczynski A, Thompson KD et al. Female authorship in major academic gastroenterology journals: a look over 20 years. Gastrointest Endosc 2015;81:1440-1447.

14. Hossain Naveed, Hossain Tanvir. Motivating factors and barriers towards choosing a career in general surgery: a review of the literature. Int Surg J 2015;2:121-124.

15. Piper CL, Scheel JR, Lee CI et al. Gender trends in radiology authorship: a 35-year analysis. Am J Roentgenol 2016;206:3-7.
16. Smith KH, Hallett RJ, Wilkinson-Smith V et al. Results of the British Society of Gastroenterology supporting women in gastroenterology mentoring scheme pilot. Frontline Gastroenterol 2019;10:50-55.

17. Girod S, Fassiotto M, Grewal D et al. Reducing implicit gender leadership bias in academic medicine with an educational intervention. Acad Med 2016;91:1143-1150.

18. Spector ND, Overholser B. Examining gender disparity in medicine and setting a course forward. JAMA Netw Open 2019;2:e196484.

19. Oxentenko AS, Burke CA, Kane SV. Women in gastroenterology: involvement in our national organizations. Gastrointest Endosc. 2016;84:384.

20. Westring A, McDonald JM, Carr P et al. An integrated framework for gender equity in academic medicine. Acad Med 2016;91:1041-1044.

Publisher's Note Springer Nature remains neutral with regard to jurisdictional claims in published maps and institutional affiliations. 